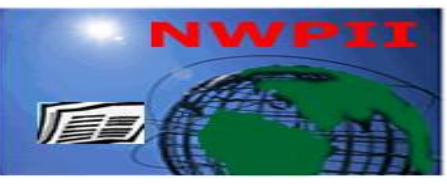

American Journal of Biomedical Sciences

ISSN: 1937-9080

nwpii.com/ajbms

\title{
The Environmental and Clinical Implicatio of Helmithic Infection: A Brief Review
}

\section{Michael A.OKUNGBOWA and Nosa Terry OMORODION}

Health Services Department, University of Benin, Benin city, Edo state, Nigeria,

Department of Medical Laboratory Sciences, Faculty of Basic Medical Sciences, University of Benin, Benin city, Edo state, Nigeria

"Corresponding Author

Nosa Terry Omorodion

Health Services Department University of Benin

Ugbowo, Benin city, Edo state

Nigeria

Tel:+2348136742270

Email: terry.omorodion@uniben.edu

Received:31January 2018;| Revised:13 February 2018; | Accepted:23 March 2018

\begin{abstract}
Parasite is an organism living in, with, or on another organism in parasitism. Parasites are creatures that invade a host, attach themselves externally and internally (to tissues and organs), and rob the host of nutrients. Symptoms may occur immediately or take up to 20 years for symptoms to manifest. Why in some cases it could be asymptomatic. The presentation of signs and symptoms in some food and take anthelmintic at least one time diseases may involve with helminthic infection. If you are sick with unknown cause, helmenthic infection should be concern. Protection from helminthic infection by eating cooked.
\end{abstract}

Keywords: Helminthic; Environmental; Infection

\section{Introduction}

Parasite is an organism living in, with, or on another organism in parasitism. Parasites are creatures that invade a host, attach themselves externally and internally (to tissues and organs), and rob the host of nutrients. Some parasites, such as certain worms, eventually weaken and cause disease in their gracious hosts ${ }^{[1]}$.
Parasitic worms are common in Africa, Asia, Central and South America, and are rare in countries where sanitation is practiced ${ }^{[2]}$.

Worms (nematodes) are long, naked, and boneless creatures that pass their young from eggs or cyst to larval (newly hatched worms) stage, maturing into worms in the tissues they infect, such as skin, muscle, lungs, or intestine (gut or digestive tract) ${ }^{[2]}$. 


\subsection{The Helminthic is classified in 2 groups}

1.Nematodes: Known as roundworm and

2.Platyhelminth: Known as tapeworm and flukes.

There are many kinds of roundworms in nematodes group such as Acariasis, Enterobiasis, Trichuris and strongyloides stercalaris.

\subsection{Acariasis}

Transmission is by ingestion of Acariasis eggs that are gotten from contaminated soil. Habitation of Acariasis is in the small intestinal. The patients will present the symptoms such as intestinal obstruction, liver abscess, billary acariasis and ascaris pneumonia. To diagnosis the Acariasis include: stomach X-ray, examine the eggs and mature of Acariasis in stool. The medications for treatment are albendazole, mebendazole, pyrantel pamoate and levamisol ${ }^{[3,4]}$.

\subsection{Enterobiasis}

Route of transmission: from the environment and anus to mouth, or the egg ingested through the mouth. After transmit to the body, Enterobiasis will habituate in the large intestinal and produce cysts. The symptoms and signs are emotional instability, weight loss, anorexia, fever and itchy around the anus. The onset time is gradual from 1-3 weeks. Diagnosis of Enterobiasis is by stool examination of patients, colonoscopy and serology. Recommended treatment for the infection is by swallowing of recommended medicines and everyone in the family should be treated. The medicines that should be taken is albendazole, mebendazole and pyrantel pamoate $^{[3,5]}$

\subsection{Trichurisis}

The mature of Trichurisis is found in the large intestinal. Transmission to the body is by ingestion eggs of Trichurisis. There could be no symptom if it is light infection but heavy infection may present the symptoms of hemorrhage, mucopurulent stool, dysentery with rectal prolapsed. Diagnosis of Trichurisis infection is by stool examination of patients and proctoscopy. Medicationthat should be taken is mebendazole $100 \mathrm{mg}, 3$ times a day for 3 days. Or the single dose of albendazole $400 \mathrm{mg}^{[6,7,8]}$

\subsection{Strongyloides stercolaris}

Larva of Strongyloides stercolaris gotten from contaminated soil, transmission is by piercing of the human skin. The presentations of symptoms are different up to the age of Strongyloides stercolaris. The larva of Strongyloides stercolaris causes cough, pulmonary edema. The mature S. stercolaris causes chronic diarrhea and malnutrition and may develop to the serious problem, like respiratory failure, brain damage and whole body inflammation. Medicines of choice are albendazole, mebendazole, tribendazole and ivermectin ${ }^{[8]}$.

\subsection{Ancylostomiasis}

Habituate in small intestinal, transmit by piercing through the foot. The larva may cause irritation around the affected area, fever and lung inflammation. The adult worm causes anemia and intestinal ulcer. Diagnose of the infection iis by examination of the eggs of Ancylostomiasis in stool. Albendazole, Mebendozole, Pyrantel pamoate and levamisole are the medicines of choice in this case $[4,8]$

\subsection{Transmission}

Soil-transmitted helminths are transmitted by eggs that are passed in the faeces of infected people. Adult worms live in the intestine where they produce thousands of eggs each day. In areas that lack sufficient sanitation, these eggs contaminate the soil. This can happen in numerous ways:

eggs that are attached to vegetables are eaten when the vegetables are not carefully cooked, washed or peeled;

eggs are ingested from contaminated water sources;

eggs are ingested by children who play in the contaminated soil and then put their hands in their mouths without washing them.

In addition, hookworm eggs hatch in the soil, releasing larvae that mature into a form that can actively penetrate the skin. People become infected with hookworm primarily by walking barefooted on the contaminated soil.

There is no direct person-to-person transmission, or infection from fresh faeces, because eggs passed in faeces need about 3 weeks to mature in the soil before they become infective. Since these worms do not proliferate in the human 
host, re-infection occurs only as a result of contact with infective stages in the environment ${ }^{[2,3,4]}$

\section{Symptoms as affect various part of the body}

Symptoms may occur immediately or take up to 20 years for symptoms to manifest. Why in some cases it could be asymptomatic.

Digestive tract (stomach, instestine, liver): Abdominal pain or bloating, weakness, diarrhea, loss of appetite, weight loss, vomiting, anemia, malnutrition with deficiencies of vitamins (B 12) minerals (iron), fats, and protein. Itching around anus and vagina, inability to sleep, urinating in bed, and abdominal pain seen in pinworm infections ${ }^{[3,4]}$.

Lungs: Coughing, coughing blood, difficulty in breathing

Allergic Reaction: Skin rash, skin itches and itches around the anus (pinworm).

SKIN: Eruptions, fluid-filled sacs called vesicles or bullae, intense facial swelling, especially around the eyes ${ }^{[3]}$.

Brain: Headache, seizures, vomiting, visual changes, dizziness ${ }^{[3,4]}$

Liver: abdominal pain, enlarged tender liver, fever, diarrhea, yellowish skin

Lymphatic tissues: Swollen elephant-like legs or testicles.

Bladder: Blood in urine, pain below the belly button, and pain upon urination

Heart: Irregular heart rate.

Bones: Fracture ${ }^{[3,4]}$.

\section{Causes of helmithic infections}

\subsection{Trematodes or flukes}

Shistosomiasis (Sh) -- after the adult worm lays eggs, they hatch into Cercariae, infecting the brain and muscle. They come from eating raw or undercooked fish or meat from tiny fluke that lives off snails, fish, Crabs, and vegetation in fresh water rivers and ponds. The Cercariae penetrate through a cut in human skin and migrate to different parts of the body e.g. intestine, liver, lungs, bladder, etc. and cause various illnesses. Eating undercooked crab, crayfish, or smoked and pickled fish are also ways of contacting the infection ${ }^{[4,7]}$.

Paragonimiasis (oriental lung fluke), Clonorchiasis (oriental liver fluke) -- are examples of many different types of fluke, with variety of conditions associated with them.

\subsection{Cestodes or tapeworms}

These worms have many segments. They often invade the digestive tract, where they get their nutrition from their host ${ }^{[4]}$.

Diphyllobothriasis or fish tapeworm infection (intestine), Taeniasis Saginata or beef tapeworm infection (intestine), Cysticercosis (Cy) or pork tapeworm all come from animals that have eaten the eggs of these worms ${ }^{[2,4]}$.

Echinococcosis (Ec) or hydatid diseases are caused by variety of worms infecting animals that ingest the eggs, such as rodents, dogs, sheep, cattle, and humans. They can invade and grow in many organs, such as liver, bone, heart, and brain.

Hymenolepiasis Nana and Diminuta larval stage occurs inside insects and fleas (rats and mice) and if these insects are eaten, as in uncooked cereals, they can grow in the intestine and cause problems ${ }^{[2]}$.

\subsection{Cestode(Tapeworm) group}

Taenia solium and opisthochis viverriini are the important helminthics in cestode (Tapeworm) group $^{[1]}$.

\subsection{Taenia solium}

The carrier of Taenia solium is pig. Transmit by eating larva or the eggs in the meat. The symptoms of infection present as stomach pain, nausea, vomit and weight loss. The cysticercosis (larva of Taenia solium) cause serious problems in neuron functions such as convulsion, paralysis and head pain. Diagnose by CT-Scan, MRI and examination larva in the stool. The medication for treatment the mature are niclosamide, praziquantel. And treat the larva infection with albendazole and praziquantel $^{[8]}$.

\subsection{Opisthochis viverrini}

Maturity of Opisthochis viverrini will stay in the bile. Transmit to the body by eating cyst of the helminthic in fish. The symptoms of infection are liver pain and tumor in liver (Cholangiocarsioma). Diagnosis is by examination of the eggs in the stool and ultra-sound the liver of patients. Medicines of choice are Praziquantel and Mebendazole ${ }^{[8]}$. 


\subsection{Filariasis}

- A varied group of worms that invade the skin (subcutaneous tissues) and lymphatic tissue (series of pea-sized nodes and canals that collect white blood cells and return them to the blood stream). In some cases, the eyes may also be involved. These worms are very small, and their offspring, called microfilariae, are no bigger than 250 micrometers. Examples are those carried by mosquitoes, such as Wuchereria bancrofti, Brugia malayi, and timori, and those carried by black flies, deer flies, and midges ${ }^{[1]}$.

\section{Conclusion}

The signs and symptoms may present itself in some individuals infected with helmithic infection. And in some asymptomatic but the first step is for the individual to go for checkup and get properly diagnosed. If you are sick with unknown cause, helminthic infection should be one of the major concern. Protection from helminthic infection is by cleaniness and eating well cooked food.

\section{References}

1. Parasites." UXL Encyclopedia of Science. . Retrieved December 22, 2017 from Encyclopedia.com: http://www.encyclopedia.c om/science/encyclopedias-almanacs-

transcripts-and-maps/parasites- 0

2. Clement Johnferdinand $\mathrm{m}$. Navarrete, Disturbances in Inflammatory andImmunologic. Page 4. https://www.slidedoc.us/disturbances-ininflammatory-and-immunologic-2
3. Varga M, Dumitra cu D, Piloff L, Chioreanu E.,(2001) Skin manifestations in parasite infection. Roum Arch Microbiol Immunol.60(4):359369. doi: $10.2147 /$ IJGM.S98950

4. Lakshmi SP, Palaniappan N, Arunagiri A.,(2013) Ascariasis: challenges in the diagnosis of single worm disease. $J$ Indian Med Assoc. 013;111(9):621

622. doi: 10.2147/IJGM.S98950

5. Gangopadhyay AN, Upadhyaya VD, Gupta DK, Sharma SP, Kumar V., (2007) Conservative treatment for round worm intestinal obstruction. Indian J

Pediatr 74:108

1087.https://www.ncbi.nlm.nih.gov/pubmed/1 $\underline{8174642}$

6. DiSantis DJ, Ralls PW, Balfe DM.,( 2000) The patient with suspected small bowel obstruction: imaging strategies. American College of Radiology. ACR Appropriateness Criteria.Radiology.215:121

124. doi: 10.2147/IJGM.S98950

7. Rodriguez EJ, Gama MA, Ornstein SM, Anderson WD.,(2003) Ascariasis causing small bowel volvulus. Radiographics. 23(5):

1291 - 1293. doi: 10.2147/IJGM.S98950

8. Adegnika AA, Zinsou JF, Issifou S., (2014) Randomized, controlled, assessor-blind clinical trial to assess the efficacy of single- versus repeated-dose albendazole to treat Ascaris lumbricoides, Trichuris trichiura, and hookworm infection. Antimicrob Agents Chemother. 58(5):2535 - 2540. doi: 10.1128/AAC.01317 